Article

\title{
Acoustic Improvement of Stator-Rotor Interaction with Nonuniform Trailing Edge Blowing
}

\author{
Wenjie Wang ${ }^{1,2, *}$ and Peter J. Thomas ${ }^{2}$ \\ 1 Fluid and Acoustic Engineering Laboratory, Beihang University, Beijing 100191, China \\ 2 School of Engineering, University of Warwick, Coventry CV4 7AL, UK; P.J.Thomas@warwick.ac.uk \\ * Correspondence: wangwenjie@buaa.edu.cn
}

Received: 16 May 2018; Accepted: 16 June 2018; Published: 19 June 2018

\begin{abstract}
The results of unsteady-flow simulations and experiments are discussed to investigate active noise-reduction effects on the stator-rotor interaction in a single-stage low-speed compressor with nonuniform trailing edge blowing. It is found that for the investigated type of stator-rotor interaction noise, nonuniform trailing edge blowing has beneficial noise-reducing effects. The overall aim is to demonstrate that nonuniform trailing edge blowing can compensate momentum loss and reduce the axial thrust on rotor blades. The results illustrate how nonuniform trailing edge blowing influences the sound pressure level of the blade-passing frequencies and results in active noise reduction effects. The study was conducted using a trailing edge blowing system, a four-hole dynamic flow-field measurement system, and phase lock technology. The results obtained show that nonuniform trailing edge blowing leads to substantial noise-reduction effects, lowering sound levels by more than $10 \mathrm{~dB}$ with about $5 \%$ of inlet mass flow.
\end{abstract}

Keywords: sound pressure level; stator/rotor interaction; nonuniform trailing edge blowing; active noise reduction; acoustic mode

\section{Introduction}

The continued growth of the aviation industry resulted in aviation noise being recognized as a harmful factor in everyday life. The International Civil Aviation Organization (ICAO) and airworthiness agencies of individual countries have issued a number of aircraft airworthiness standards in order to control civil aircraft noise. However, noise is not only an issue in the context of civil aviation. Even for military aircraft, noise reduction is desirable to delay the fatigue of materials and facilitate acoustic stealth. The fan and the compressor are the main sources of noise on an aeroplane. Nevertheless, the noise reduction of compressors is difficult, and has attracted substantial attention due to the complex geometry of the compressors and their multistage structure.

The trailing edge of rotating or stationary blades generates a wake that affects the aerodynamic and acoustic performances of any downstream blades. When a spinning rotor blade sweeps through the viscous vortex wake shed from an upstream stator, it becomes subject to unsteady loads, as illustrated in Figure 1. In an axial engine, auxiliary airflow is commonly used to control flow. Suction and pulsed blowing flow shows a robust ability to delay separation [1]. Tip blowing can control the tip leakage in a high-pressure turbine cascade [2]. However, the blowing flow technology has been adopted mostly for turbine blade cooling [3]. 

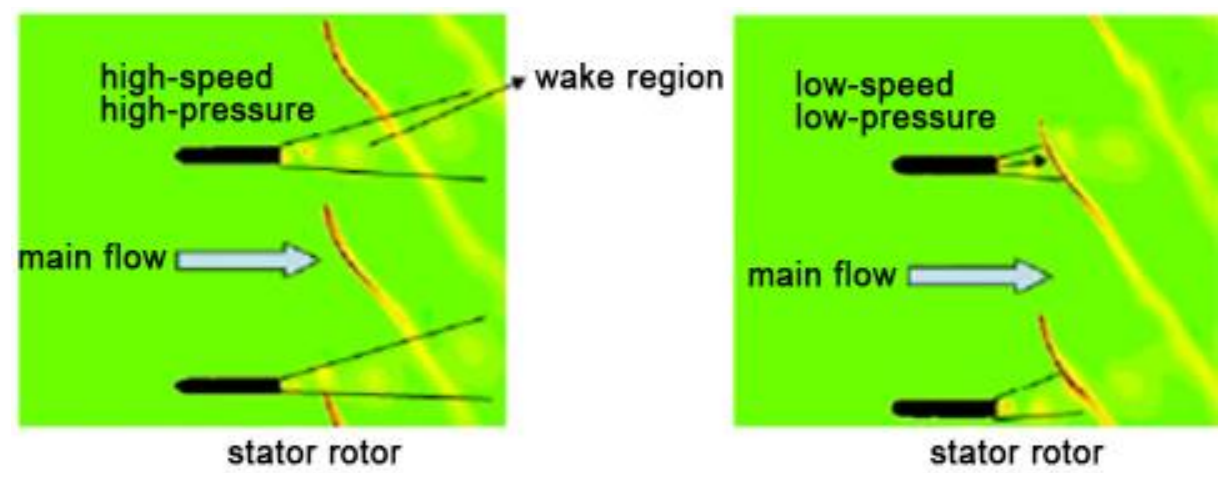

Figure 1. Interaction of rotor with stator blade trailing edge.

The compressor interstage region or stator/rotor interaction area is the core noise source in a compressor. Nacelles with liners are currently the most widely used noise reduction measures on an aeroplane. However, lined nacelles only reduce noise after it has been generated. Obviously, there exists the alternative solution of lowering compressor noise by suppressing it at the location of the source in the stator-rotor interaction area. One technique to facilitate such noise reduction is trailing edge blowing (TEB), due to its potential to compensate the momentum loss in the wake region.

The novel technology of "trailing edge blowing" for the purpose of improving the flow field emerged at the end of the last century. It was discovered when it was first applied to turbine machinery at the Massachusetts Institute of Technology that it results in greater thrust for engines. Waitz [4] and Sell [5] used TEB to reduce the rotor-stator interaction noise of a turbo fan engine, and they concluded that TEB is the preferable methodology for flow control when compared with boundary-layer suction. Leitch [6] from Virginia Polytechnic and State University continued this work to reduce downstream rotor noise with uniform TEB from the wake of an upstream stator. This was followed up by Brookfield [7,8], who investigated the effects of TEB on turbo fan engine noise, and concluded that it could be effective to uniform rotor wakes. Meanwhile, Thomas [9] used less than $1 \%$ mass flow to reduce forward radiated noise by $8 \sim 9 \mathrm{~dB}$. Yavbz [10] used TEB for a delta wing to reduce unsteady flow. In 2009, Matjaz [11] illustrated the performance of TEB when applied in different positions on a fan through calculations and experiments. In 2012, Giovanna [12] researched Mach number effects on noise. The above references reveal that TEB was mostly used on turbines with the purpose of making the flow field more uniform, but with rare concurrent acoustic research on stator-rotor interaction. Saunders [13] conducted a series of experiments on a supersonic compressor with $6 \mathrm{~dB}$ of noise reduction. Rao [14] continued Leitch's research in an anechoic chamber of Virginia Tech, and found that the strongest noise reduction of the first four order blade-passing frequency (BPF) was 3-5 dB. Feng [15] used non-inserting microphones for Rao's experiments. Thereafter, the research team at Virginia Tech [16-19] studied flow control methods, airfoil design, and acoustic measurement methods, and concluded that TEB has an obvious influence on acoustics and aerodynamics.

In this paper, the effect of nonuniform trailing edge blowing (NTEB) on the acoustic performance in a single-stage low-speed compressor is evaluated. Section 2 illustrates the structure and geometry of the single-stage low-speed compressor. It discusses the positions and sizes of the blowing holes in the stator blade, and also defines the measurement positions within the flow field and the layout of the microphones for forward and backward radiation. In Section 3, the acoustic characteristics of the duct are introduced, and the acoustic modes are presented. Section 4 describes the steady and unsteady numerical simulations. On the basis of the results from these calculations, the axial thrust is analyzed and discussed. In Section 5, the effect of trailing edge blowing is evaluated by means of considering the acoustic characteristics and the sound pressure level with and without NTEB. 


\section{Geometry and Structure of the Compressor Facilities}

Figure 2 illustrates the low-speed axial compressor; its six stator blades and 11 rotor blades were used to evaluate the acoustic characteristics. A total of 16 microphones were used, of which eight were ahead and eight were rear of the compressor. In each case, the microphones were distributed evenly in the circumferential positions. The tip radius was $0.201 \mathrm{~m}$, and the hub radius was $0.110 \mathrm{~m}$ in the axial compressor. The fan was driven by a $30-\mathrm{kW}$ frequency conversion motor, and the fan speed could reach maximum rotation rates of $8500 \mathrm{rpm}$.

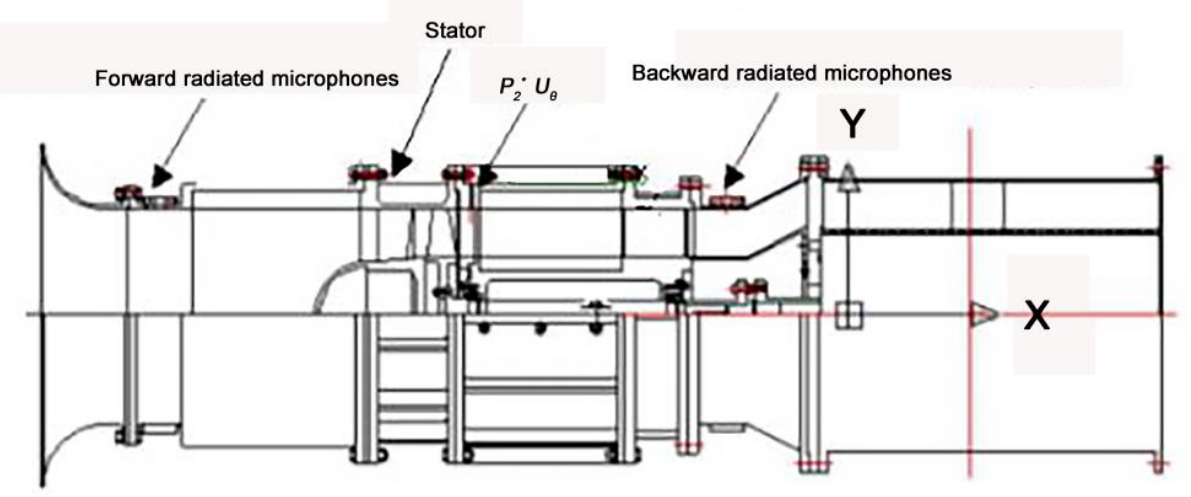

Figure 2. Single-stage low-speed axial compressor.

In order to investigate the effects of NTEB, the stator blades were rebuilt with blowing holes, as shown in the middle section of Figure 3. In Figure 3, a row of holes with different diameters enabled nonuniform blowing flows. Seven holes in the casing were arranged in the circumferential direction, as shown in the left section of Figure 3. The casing is situated downstream of two adjacent stator blades. The flow field is measured with a four-hole dynamic pressure probe. There are eight successive measurement stations, at intervals of $10 \mathrm{~mm}$, ranging from $120 \mathrm{~mm}$ to $190 \mathrm{~mm}$ along the radial direction at each position between the stator and the rotor. The phase lock technique has been used for the flow field measurement.

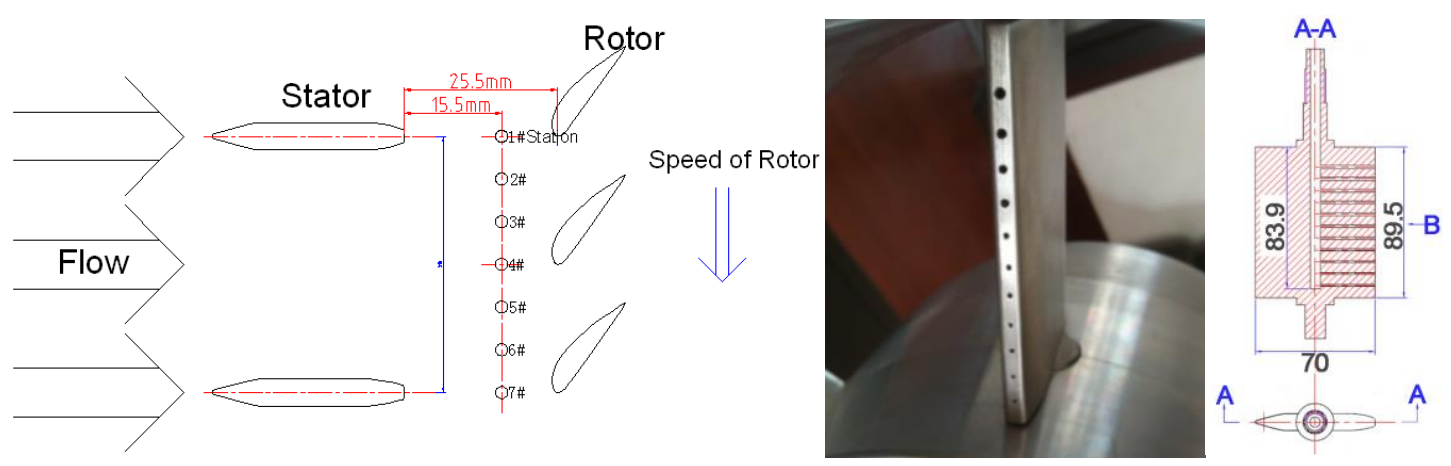

Figure 3. Low-speed axial compressor and blade with holes.

\section{Acoustic Propagation Analysis}

According to the relevant literature [20], the rotor-stator noise is evaluated by summing up the harmonics of the blade-passing frequency, and can be expressed as:

$$
\begin{gathered}
p(\vec{x}, t)=\sum_{s=-\infty}^{\infty} p_{s B}(\vec{x}) \cdot e^{-i s B \Omega t} \\
m=s B-q V
\end{gathered}
$$


where $p$ is the stator-rotor interaction noise, $x$ is the observation vector, $\Omega$ is the rotor speed, $t$ is the time, $m$ is the azimuthal mode order, $B$ is the number of rotor blades, $V$ is the number of stator blades, $s$ is the order of blade-passing frequency, and $q$ is an arbitrary integer number. The working speed of the rotor is $4500 \mathrm{rpm}$. There are 11 rotor blades and six stator blades. Therefore, the first BPF's probable maximum acoustic mode order is -1 , and the second BPF's probable maximum acoustic mode order is -2 or +4 , according to Equation (2).

The aerodynamic noise caused by the stator-rotor interaction in the compressor is distributed discretely over the blade-passing frequency, and its harmonics are given by:

$$
f=\frac{s B \Omega}{2 \pi}(s=0, \pm 1, \pm 2 \ldots \ldots)
$$

For a rotor speed of $4500 \mathrm{rpm}$, the first two orders of the blade-passing frequencies as shown in Figure 4 are calculated to be:

$$
f_{1}=825 \mathrm{~Hz} f_{2}=1650 \mathrm{~Hz}
$$

Sound can propagate forward and backward when it meets the transport condition [21], which, for the hard wall duct, is given by:

$$
\frac{s^{2} B^{2} \Omega^{2}}{c_{0}^{2}}-\beta^{2} k_{m, n}^{2}>0
$$

On the basis of the propagation condition, sound can propagate in a duct when the sound frequency is higher than the cut-off frequency. The cut-off frequency of a duct can be expressed as:

$$
f_{c}=\frac{c k_{m, n}}{2 \pi} \sqrt{1-M_{u}^{2}}
$$

where $c$ is the sound velocity, $k$ is the eigenvalue of Green's function, and $M$ is the Mach number.

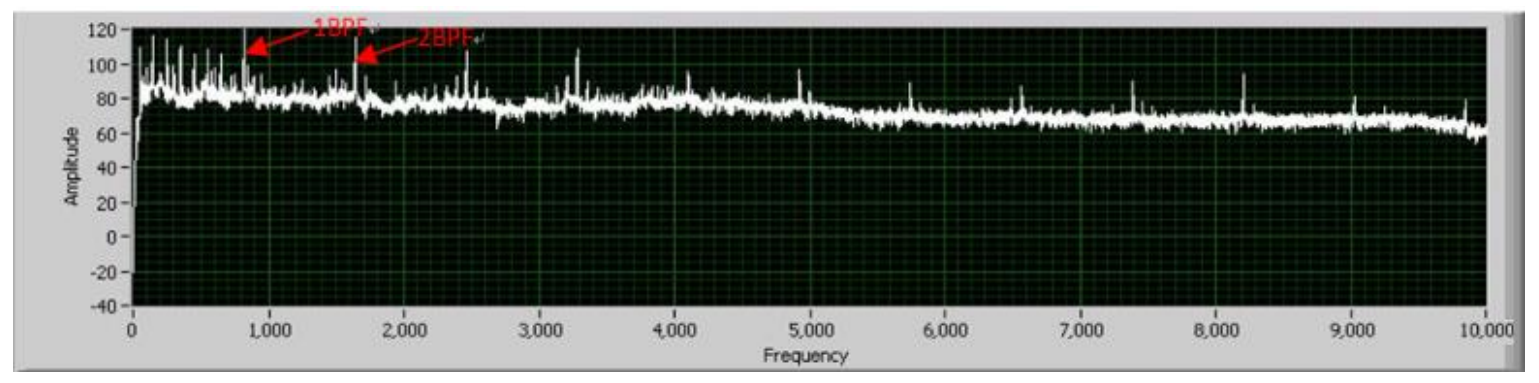

Figure 4. Acoustic frequency spectrum.

For forward transport in a circular duct, the cut-off frequency of mode $(-1,0)$ is:

$$
f_{c}=493 H z f_{1}
$$

The cut-off frequency of mode $(+4,0)$ is:

$$
f_{c}=1421 H z f_{1}
$$

For backward transport in a circular duct, the cut-off frequency of mode $(-1,0)$ is:

$$
f_{c}=351 H z f_{1}
$$

while the cut-off frequency of mode $(+4,0)$ is:

$$
f_{c}=1360 H z f_{2}
$$


Therefore, sound can be transported forward and backward in the low-speed axial compressor.

\section{Simulation Results}

In the current paper, we focus on the influence of NTEB on the acoustic characteristics of stator-rotor interaction. On the basis of the compressor geometry and the actual working parameters introduced in Section 2, numerical simulations were conducted to illustrate steady and unsteady conditions. We adopt the NUMECA software to obtain trends and characteristic curves in the range of the working parameters. The axial thrust of the blade surface in the calculation is analyzed in the NUMECA_Fine_Turbo, where the axial thrust is a statistical result of the static pressure of the blade surface and the friction force of the fluid.

The turbulent working variable obeys the transport equation:

$$
\frac{\partial v}{\partial t}+\vec{V} \cdot \nabla \widetilde{v}=\frac{1}{\sigma}\left\{\nabla \cdot\left[\left(v+\left(1+c_{b 2}\right) \widetilde{v}\right) \nabla \widetilde{v}\right]-c_{b 2} \widetilde{v} \Delta \widetilde{v}\right\}+Q
$$

where $\vec{V}$ is the velocity vector, $Q$ is the source term, and $\sigma, c_{b 2}$ are constants.

The source term includes a production term $P$ and a destruction term:

$$
Q=\widetilde{v} P(\widetilde{v})-\widetilde{v} D(\widetilde{v})
$$

The axial thrusts of the steady and unsteady time average are shown in Figure 5. The axial thrust in the flow path fluctuated around the time-averaged value. The maximum amplitude fluctuation with and without TEB is about $6.56 \mathrm{~N}$ and $2.52 \mathrm{~N}$, respectively. From the two plots in Figure 5, the axial thrust of the downstream rotor with NTEB is $2.3 \mathrm{~N}$ lower than without NTEB.

The rotors speed was measured to be $4472.7 \mathrm{rpm}$ when the rotor speed was set at a nominal speed of $4500 \mathrm{rpm}$. Meanwhile, since the rotor number is approximated as 12 in the simulations, the first-order BPF should be $4472.7 / 60 \times 12=894.54 \mathrm{~Hz}$, and some of the BPFs are illustrated in Figure 6 . The axial thrust of the rotor blades with NTEB is compared with results without NTEB at the first five BPFs in Figure 6. The figure clearly reveals that the axial thrust of the downstream rotor is significantly reduced, and that the vibration amplitudes have also decreased considerably.

The axial thrusts on the downstream rotor, with and without NTEB and at different blade-passing frequencies, are illustrated in Table 1. Since the periodic flow interaction with the rotor in rotation induces the axial thrust on the rotor blade, the unsteady loads at blade-passing frequencies can be obviously reduced with NTEB. The most significant reduction of the unsteady load resulting from NTEB is $63.83 \%$ at the first BPF.
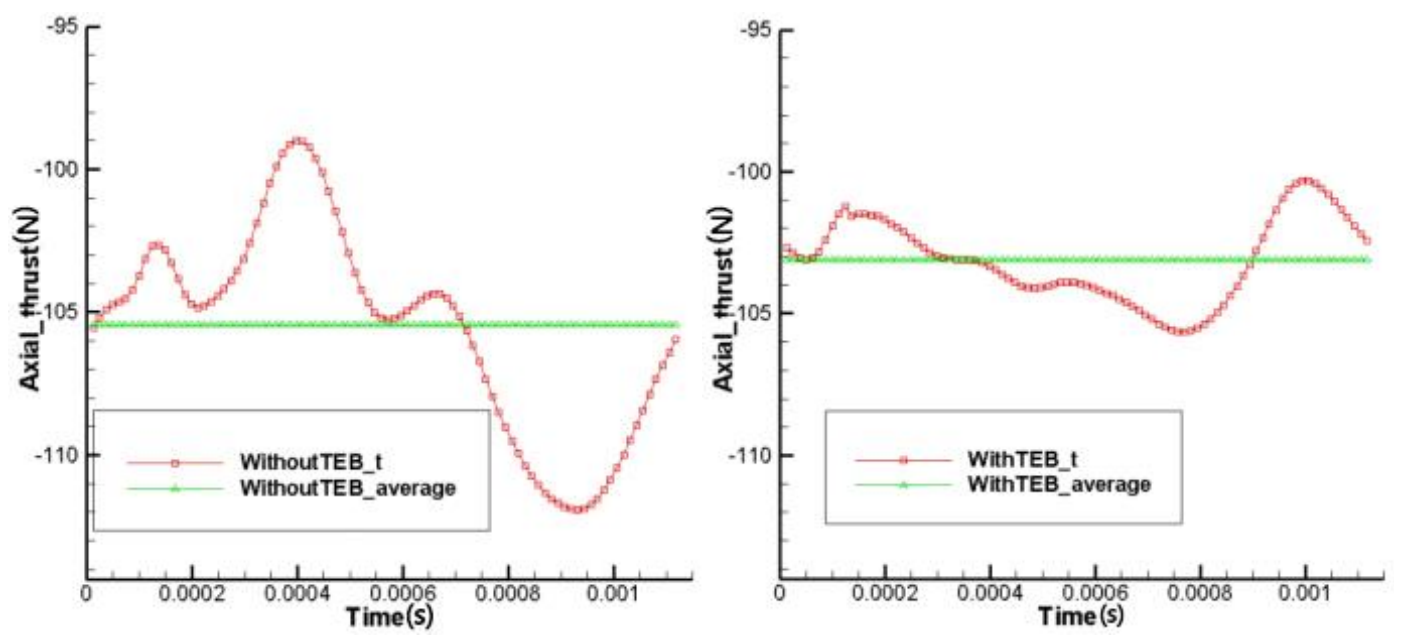

Figure 5. Axial thrust with and without nonuniform trailing edge blowing (NTEB). 


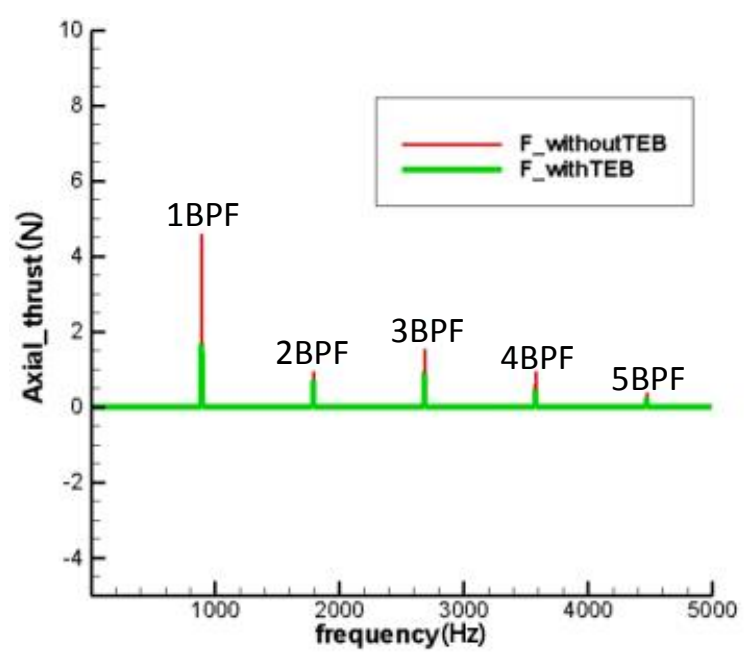

Figure 6. Blade-passing frequencies of axial thrust.

Table 1. The first five orders of blade-passing frequencies (BPF).

\begin{tabular}{cccccc}
\hline $\begin{array}{c}\text { BPF Order } \\
\text { Frequency }\end{array}$ & $\begin{array}{c}\mathbf{1}^{\text {st }} \mathbf{B P F} \\
\mathbf{( 8 9 4 . 5 4} \mathbf{~ H z})\end{array}$ & $\begin{array}{c}\mathbf{2}^{\text {nd }} \mathbf{B P F} \\
\mathbf{( 1 7 8 9 . 0 8} \mathbf{~ H z})\end{array}$ & $\begin{array}{c}\mathbf{3}^{\text {rd }} \mathbf{B P F} \\
(\mathbf{2 6 8 3 . 6 2} \mathbf{H z})\end{array}$ & $\begin{array}{c}\mathbf{4}^{\text {th }} \mathbf{B P F} \\
\mathbf{( 3 5 7 8 . 1 6} \mathbf{~ H z})\end{array}$ & $\begin{array}{c}\mathbf{5}^{\text {th }} \mathbf{B P F} \\
\mathbf{( 4 4 7 2 . 7 ~} \mathbf{~ H z})\end{array}$ \\
\hline Without NTEB (N) & 4.59 & 0.95 & 1.54 & 0.95 & 0.37 \\
With NTEB (N) & 1.66 & 0.69 & 0.88 & 0.44 & 0.23 \\
Reduction Ratio & $63.83 \%$ & $27.37 \%$ & $42.86 \%$ & $53.68 \%$ & $37.83 \%$ \\
\hline
\end{tabular}

\section{Experimental Results}

In this section, the experimental results of the acoustics and the flow-field measurements are discussed. The acoustic results are divided into forward and backward noise transmission. In both of these cases, acoustic modes at the first two orders of BPF are presented and analyzed. In the case of the flow field, measurement results for the flow-field pressure distribution at the stator/rotor interaction region are presented for different blowing conditions.

\subsection{Flow Field Results}

The results presented are for measurement location \#1 which is, as indicated in Figure 3, located downstream and in the wake of the stator blade. The speed of the rotor was measured to be $4472.7 \mathrm{rpm}$ $(f=74.55 \mathrm{~Hz})$. The added mass flows of NTEB ranged from $0 \mathrm{~m}^{3} / \mathrm{h}$ to $6 \mathrm{~m}^{3} / \mathrm{h}$. The maximal added mass flow is less than $5 \%$ of the total inlet flow. The data sampling frequency is $20 \mathrm{kHz}$. A phase-locked averaging technology was adopted for the data processing, which was facilitated through a Hall sensor for phase locking. Since there will be vortices in the wake region, and because the dynamic four-hole probe cannot be used to measure the vortex speed, the dynamic pressure from one hole of the probe is analyzed, and the results are shown in Figure 7.

Figure 7 reveals that the axial pressure adopts negative values in the wake region, which indicates a loss of axial velocity. However, with increasing added mass flow, those negative values have a positive growth. When the added mass flow has its maximum of $6.0 \mathrm{~m}^{3} / \mathrm{h}$, the regions displaying negative pressure values are much smaller. In this case, the stator wake is obviously improved. Meanwhile, the period $(\mathrm{T}=11)$ induced by the stator wake and rotor rotation in Figure 7 reflects the number and contours of rotor blades. 

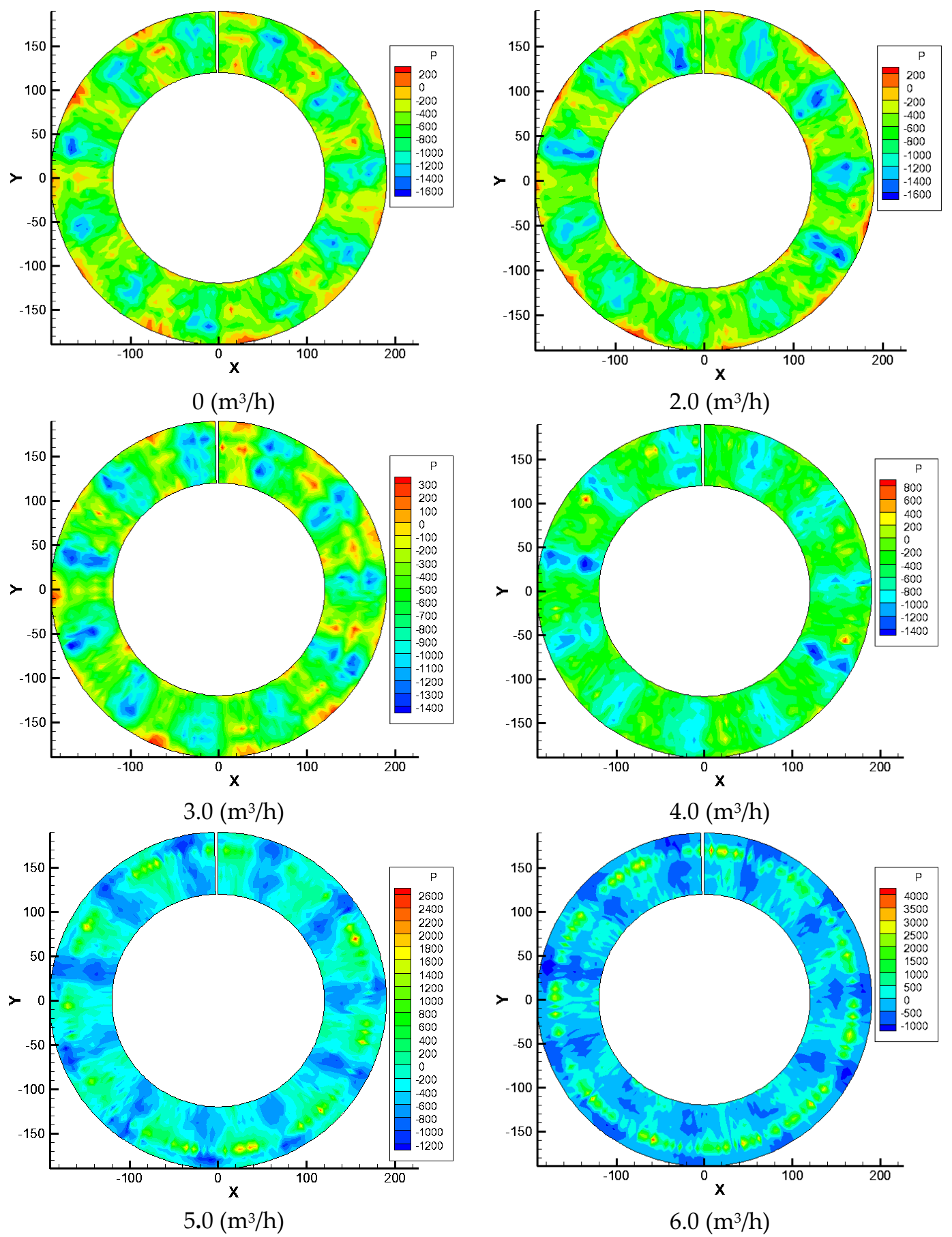

Figure 7. Dynamic pressure for different blowing-flow conditions.

\subsection{Acoustic Results}

\subsubsection{Noise Transmission in the Forward Direction}

The sound pressure levels (SPL) of the first and second-order BPF of the noise radiated forward are presented in Figure 8. The added mass flows of NTEB ranged, as for Figure 7, between $0 \mathrm{~m}^{3} / \mathrm{h}$ to $6 \mathrm{~m}^{3} / \mathrm{h}$. The maximum acoustic modes of the first and second-order BPF in Figure 4 are discussed in Section 3. 


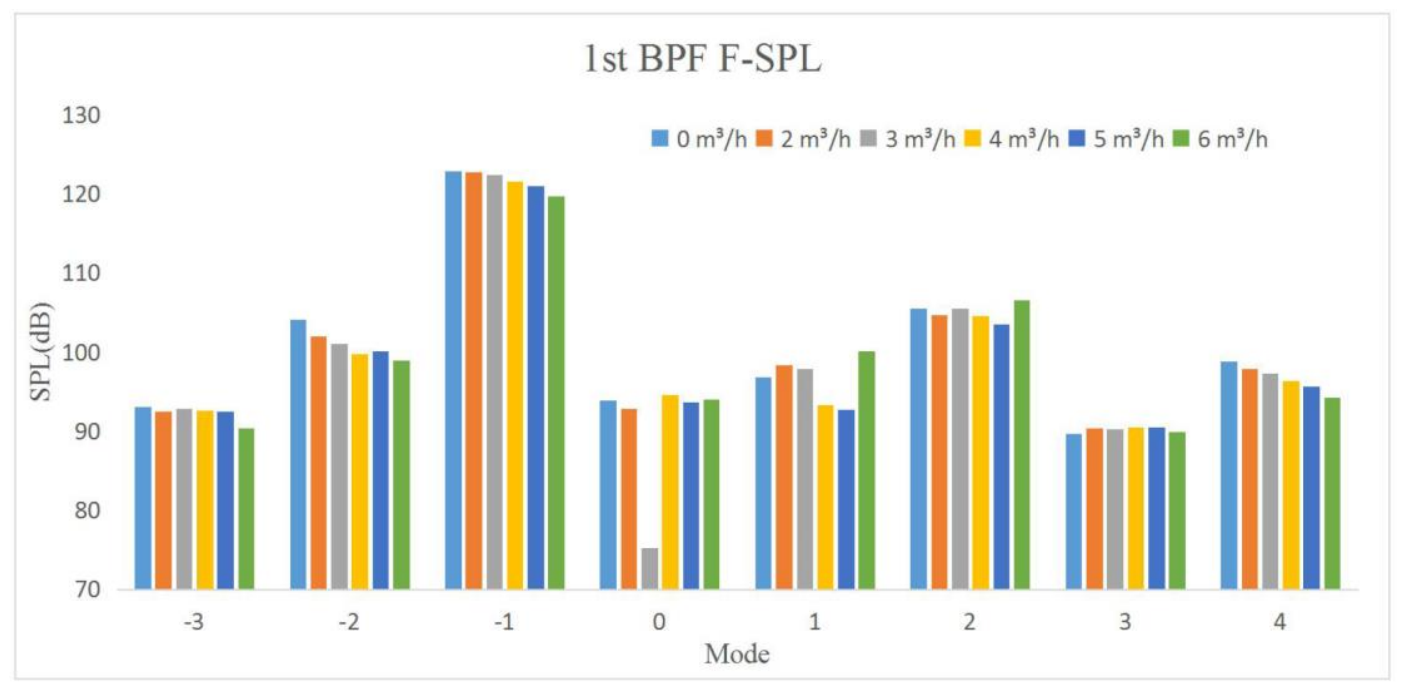

Sound pressure level (SPL) of the first-order BPF.

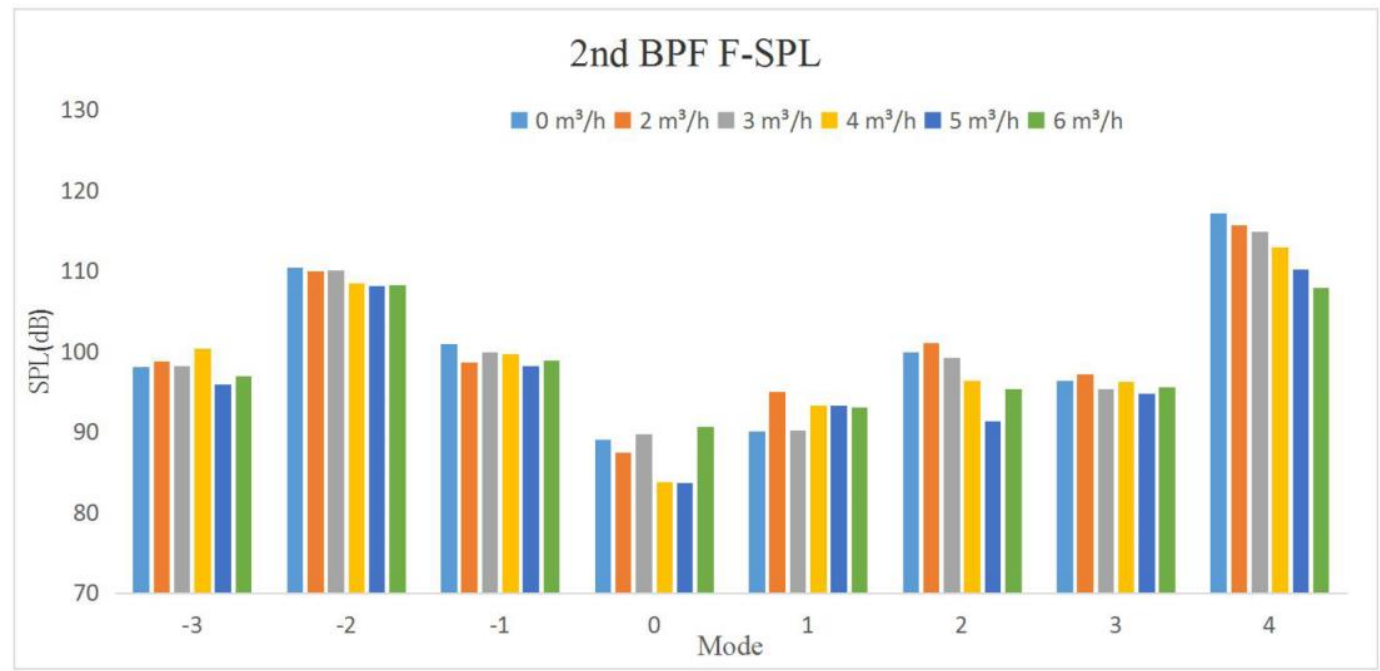

SPL of the second-order BPF

Figure 8. SPL of the first and second-order BPF.

As revealed by Figure 8, the maximum acoustic modes agree with the acoustic theory of stator/rotor interaction, as illustrated in Section 3. The noise reduction of the maximum acoustic modes for the first two BPFs show a decrease of the SPL with increasing added mass flow. The SPL of the first-order BPF is reduced by more than $3.2 \mathrm{~dB}$ at $6 \mathrm{~m}^{3} / \mathrm{h}$ added mass flow for the maximum acoustic mode. Meanwhile, the largest noise reduction is more than $9.2 \mathrm{~dB}$, with $6 \mathrm{~m}^{3} / \mathrm{h}$ added mass flow at mode $(+4)$ of the second-order BPF. Similar observations are made for the other modes of the first two BPFs. The overall effect of TEB is to establish a trend to reduce noise for any mode at any mass flow rate.

\subsubsection{Noise Transmission in the Backward Direction}

Figure 9 displays the results corresponding to those in Figure 8, but in this case for backward noise transmission. The noise levels that radiated backwards and forwards were measured simultaneously. The overall trends displayed by the results for the noise that radiated backwards mirrored those for forward radiation, in particular for the second-order BPF. However, noise reductions of the first-order 
BPF displayed a more complex scenario, where many acoustic modes revealed a decrease of the SPL with NTEB. With the maximum NTEB flow, the SPL reduction is just above $2.3 \mathrm{~dB}$ at mode $(-1)$ of the first-order BPF, while the reduction is more than $10 \mathrm{~dB}$ at both maximum acoustic modes $(-2$ and +4$)$ of the second-order BPF.

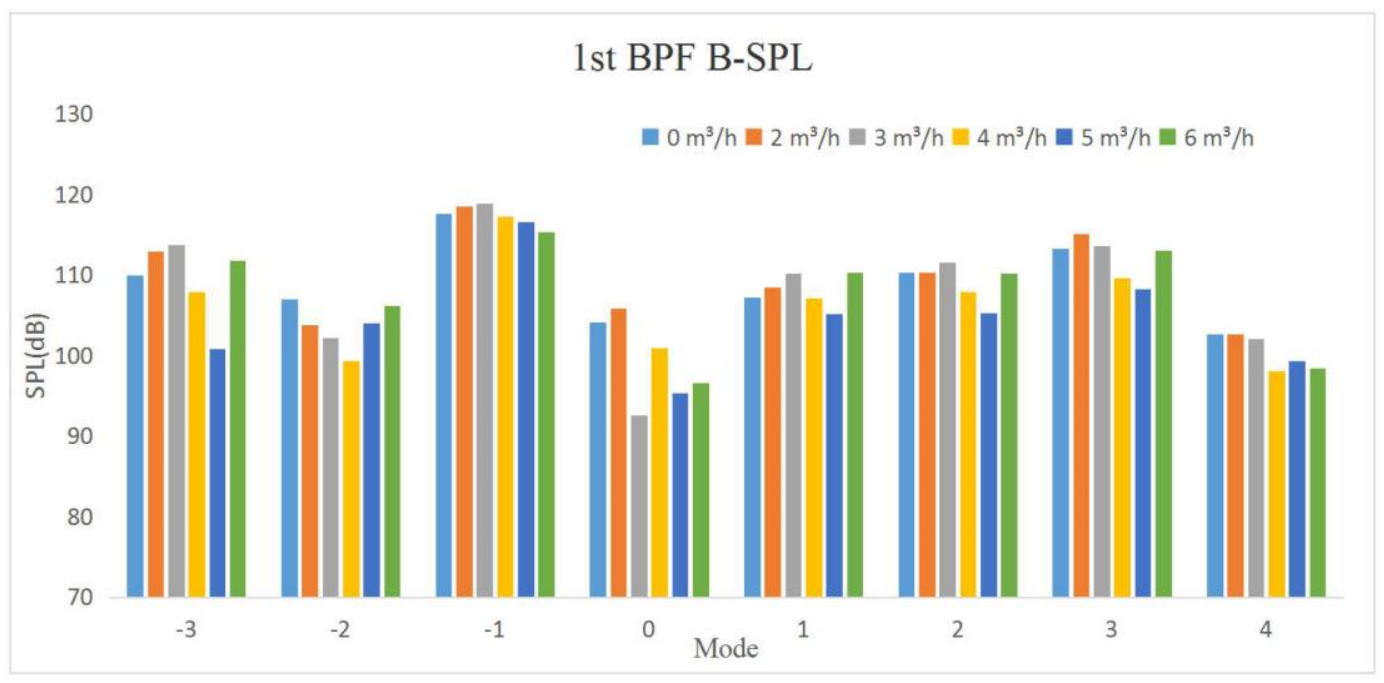

SPL of the first-order BPF.

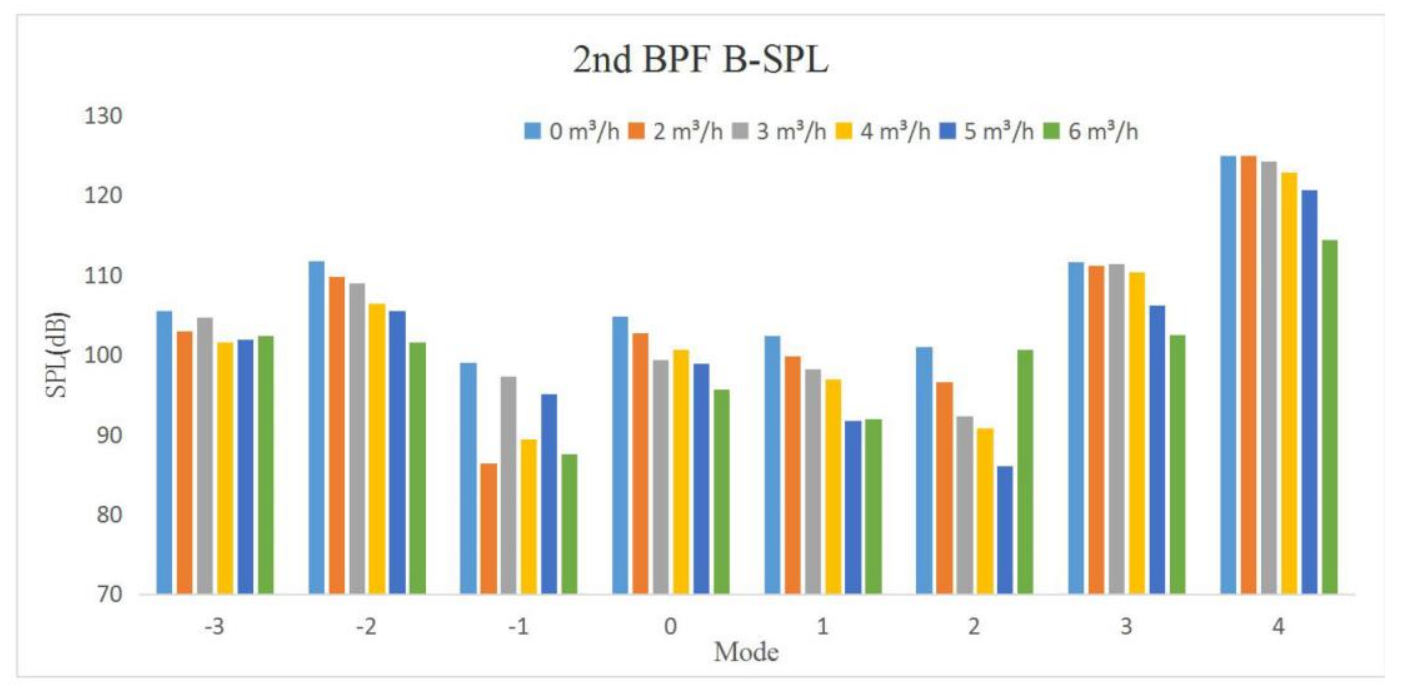

SPL of the second-order BPF

Figure 9. SPL of the first and second-order BPF.

\subsubsection{OASPL Analysis}

Section 5.2.1 has shown that NTEB results in beneficial effects of noise reduction on the first and second-order BPF of forward radiation when the SPL was found to be reduced for increasing levels of NTEB mass flow. However, for the first-order BPF of backward radiation in Section 5.2.2, noise-reduction effects were not obvious, and it was even observed that NTEB can have detrimental effects. These trends are the same as those for the overall sound pressure level (OASPL) analysis of the first two orders, as presented in Table 2, where F-OASPL is the overall sound pressure level of forward radiation noise, and B-OASPL is the overall sound pressure level of backward radiation noise. 
The biggest OASPL reduction was more than $9 \mathrm{~dB}$, which is a little smaller than the SPL reduction of the maximum acoustic mode.

Table 2. Overall sound pressure level (OASPL) reduction of the first two orders (dB). F-OASPL: overall sound pressure level of forward radiation noise, B-OASPL: overall sound pressure level of backward radiation noise.

\begin{tabular}{|c|c|c|c|c|c|c|}
\hline & & $2 \mathrm{~m}^{3} / \mathrm{h}$ & $3 \mathrm{~m}^{3} / \mathrm{h}$ & $4 \mathrm{~m}^{3} / \mathrm{h}$ & $5 \mathrm{~m}^{3} / \mathrm{h}$ & $6 \mathrm{~m}^{3} / \mathrm{h}$ \\
\hline \multirow{2}{*}{ F-OASPL } & $1^{\text {st }} \mathrm{BPF}$ & 0.35 & 0.78 & 1.51 & 2.10 & 2.45 \\
\hline & $2^{\text {nd }} \mathrm{BPF}$ & 0.66 & 1.28 & 2.49 & 4.46 & 4.60 \\
\hline \multirow{2}{*}{ B-OASPL } & $1^{\text {st }} \mathrm{BPF}$ & -1.02 & -0.73 & 2.83 & 3.65 & 0.65 \\
\hline & $2^{\text {nd }} \mathrm{BPF}$ & 0.92 & 1.42 & 3.00 & 5.05 & 9.01 \\
\hline
\end{tabular}

In order to present the NTEB effect on every channel in the compressor duct, the OASPL of every channel is calculated by a linear weighted sum. The OASPL reduction of the whole compressor duct is computed in comparison to the values obtained for measurements with no added mass flow. The data obtained for the forward and backward radiation modes are displayed in Table 3, which is illustrated according to the Parseval theory.

Table 3. OASPL reduction of circumferential channels (dB).

\begin{tabular}{|c|c|c|c|c|c|c|c|c|c|c|}
\hline & & $\operatorname{ch} 1$ & $\operatorname{ch} 2$ & $\operatorname{ch} 3$ & $\operatorname{ch} 4$ & ch5 & $\operatorname{ch} 6$ & ch7 & ch8 & OASPL \\
\hline \multirow{5}{*}{ F-OASPL } & $2 \mathrm{~m}^{3} / \mathrm{h}$ & 0.28 & 0.15 & 0.16 & -0.10 & 0.43 & 0.45 & 0.04 & 0.15 & 0.21 \\
\hline & $3 \mathrm{~m}^{3} / \mathrm{h}$ & 0.43 & 0.42 & 0.29 & -0.39 & 0.55 & 0.46 & 0.13 & 0.14 & 0.27 \\
\hline & $4 \mathrm{~m}^{3} / \mathrm{h}$ & 0.80 & 1.51 & 1.08 & 0.57 & 1.44 & 1.41 & 0.58 & 0.51 & 0.98 \\
\hline & $5 \mathrm{~m}^{3} / \mathrm{h}$ & 1.16 & 2.39 & 1.89 & 1.04 & 2.18 & 2.35 & 1.03 & 0.89 & 1.59 \\
\hline & $6 \mathrm{~m}^{3} / \mathrm{h}$ & 1.06 & 3.27 & 2.36 & 0.07 & 2.82 & 2.53 & 0.68 & 1.05 & 1.68 \\
\hline \multirow{5}{*}{ B-OASPL } & $2 \mathrm{~m}^{3} / \mathrm{h}$ & -0.25 & -0.06 & -0.40 & 0.22 & 0.28 & 0.30 & -0.36 & 0.25 & -0.08 \\
\hline & $3 \mathrm{~m}^{3} / \mathrm{h}$ & 0.57 & 0.23 & -0.11 & -0.14 & 0.51 & 0.21 & -0.44 & 0.29 & 0.03 \\
\hline & $4 \mathrm{~m}^{3} / \mathrm{h}$ & 1.11 & 0.83 & 0.47 & 0.34 & 1.41 & 0.92 & 0.08 & 0.72 & 0.60 \\
\hline & $5 \mathrm{~m}^{3} / \mathrm{h}$ & 0.89 & 1.17 & 0.35 & 0.47 & 1.86 & 1.29 & 0.52 & 0.70 & 0.78 \\
\hline & $6 \mathrm{~m}^{3} / \mathrm{h}$ & 1.13 & 1.13 & 0.55 & 0.42 & 3.02 & 1.41 & 0.11 & 0.21 & 0.76 \\
\hline
\end{tabular}

Table 3 reveals that most of the channels displayed a reduction in the OASPL for both the forward and backward cases. While there exists an OASPL increase for some channels, at lower levels of TEB flow, the increments of the increase are closer to zero. Nevertheless, the increase of noise levels at some of the channels for NTEB do have an overall noise reduction, as revealed by the data in the last column of Table 3. The maximum value of noise reduction observed at any of the channels is about $3 \mathrm{~dB}$. Therefore, in summary, NTEB has been shown to have a noise reduction effect on the OASPL in the forward as well as backward radiation modes.

\section{Summary and Conclusions}

The noise reduction effect on stator-rotor interaction arising from different levels of NTEB mass flow was investigated. Unsteady-flow simulations were conducted to illustrate the mechanism that NTEB can compensate the momentum loss and influence the axial thrust on the rotor blades. Flow field measurement contours obtained within the stator-rotor interaction region revealed that the pressure loss decreases with successively increasing levels of NTEB flow. Acoustic measurements of the sound pressure levels in forward and backward radiation have shown that NTEB leads to a noise reduction by more than $10 \mathrm{~dB}$ at the maximum acoustic mode. Forward radiation is always reduced with NTEB; however, in backward radiation, there are some small increases, but overall a reduction.

Author Contributions: W.W. did the measurements, data processing, and contributed to the writing. W.W. and P.J.T. contributed to the revisions and discussions of the contents. 
Funding: This research was funded by China Scholarship Council (No. 201809110025).

Acknowledgments: We acknowledge the valuable comments by editors and anonymous reviewers.

Conflicts of Interest: The authors declare no conflict of interest.

\section{References}

1. Wilson, J.; Schatzman, D.; Arad, E. Suction and Pulsed-Blowing Flow Control Applied to an Axisymmetric Body. AIAA J. 2013, 51, 2432-2446. [CrossRef]

2. Volino, R.J. Control of Tip Leakage in a High-Pressure Turbine Cascade Using TipBlowing. J. Turbomach. 2017, 139, 061008. [CrossRef]

3. Khojasteh, A.R.; Wang, S.F.; Peng, D. Structure analysis of adiabatic film cooling effectiveness in the near field of a single inclined jet: Measurement using fast-response pressure-sensitive paint. Int. J. Heat Mass Transf. 2017, 110, 629-642. [CrossRef]

4. Waitz, I.A.; Brookfield, J.M.; Sell, J.; Hayden, B.J. Preliminary Assessment of Wake Management Strategies for Reduction of Turbomachinery Fan Noise. J. Propuls. Power 1996, 12, 958-966. [CrossRef]

5. Sell, J. Cascade Testing to Assess the Effectiveness of Mass Addition/Removal Wake Management Strategies for Reduction of Rotor-Stator Interaction Noise. Ph.D. Thesis, Massachusetts Institute of Technology (MIT), Cambridge, MA, USA, 1996.

6. Leitch, T.A.; Saunders, C.A.; Ng, W.F. Reduction of Unsteady Stator Rotor Interaction Using Trailing Edge Blowing. J. Sound Vib. 2000, V235, 235-245. [CrossRef]

7. Brookfield, J. Turbofan Rotor/Stator Interaction Noise Reduction through Trailing Edge Blowing. Ph.D. Thesis, Massachusetts Institute of Technology (MIT), Cambridge, MA, USA, 1998.

8. Brookfield, J.; Waitz, I.A. Trailing-edge blowing for reduction of turbomachinery fan noise. J. Propuls. Power 2000, 16, 57-64. [CrossRef]

9. Thomas, A.L.; Saunders, C.A.; Ng, W.F. Reduction of unsteady stator/rotor interaction using trailing edge blowing. J. Sound Vib. 2000, 235, 235-245.

10. Yavuz, M.M.; Rockwell, D. Control of flow structure on delta wing with steady trailing-edge blowing. AIAA J. 2006, 3, 493-501. [CrossRef]

11. Matjaz, E.; Brance, S.; Marko, H.; Matevz, D. Numerical and experimental investigation of axial fan with trailing edge self-induced blowing. Forsch. Ingenieurwes 2009, 73, 129-138.

12. Giovanna, B.; Alessandro, A.; Claudio, M.; Luca, C. Experimental investigation of the effects of blowing conditions and Mach number on the unsteady behavior of coolant ejection through a trailing edge cutback. Int. J. Heat Fluid Flow 2012, 37, 37-50.

13. Saunders, C.A. Noise Reduction in an Axisymmetric Supersonic Inlet Using Trailing Edge Blowing. Ph.D. Thesis, Virginia Polytechnic and State University, Blacksburg, VA, USA, 1998.

14. Rao, N.M. Reduction of Unsteady Stator-Rotor Interaction by Trailing Edge Blowing Using MEMS Based Microvalves. Ph.D. Thesis, Virginia Polytechnic and State University, Blacksburg, VA, USA, 1998.

15. Feng, J.W. Active Control for Reduction of Unsteady Stator-Rotor Interaction in a Turbofan Simulator. Ph.D. Thesis, Virginia Polytechnic and State University, Blacksburg, VA, USA, 2000.

16. Bailie, S.T. Effect of Inlet Guide Vane Flow Control on Forced Response of a Transonic Fan. Ph.D. Thesis, Virginia Polytechnic and State University, Blacksburg, VA, USA, 2003.

17. Craig, M.E. Trailing Edge Blowing of Model Fan Blades for Wake Management. Ph.D. Thesis, Virginia Polytechnic and State University, Blacksburg, VA, USA, 2005.

18. Tweedie, S. Experimental Investigation of Flow Control Techniques to Reduce Hydroacoustic Rotor-Stator Interaction Noise. Ph.D. Thesis, Virginia Polytechnic and State University, Blacksburg, VA, USA, 2006.

19. Halasz, C.W. Advanced Trailing Edge Blowing Concepts for Fan Noise Control Experimental Validation. Ph.D. Thesis, Virginia Polytechnic and State University, Blacksburg, VA, USA, 2005.

20. Goldstein, M.V. Aeroacoustics; McGraw-Hill Book: New York, NY, USA, 1976.

21. Sun, X.; Zhou, S. Aeroacoustics; National Defense Industry Press: Beijing, China, 1994.

(C) 2018 by the authors. Licensee MDPI, Basel, Switzerland. This article is an open access article distributed under the terms and conditions of the Creative Commons Attribution (CC BY) license (http://creativecommons.org/licenses/by/4.0/). 